\title{
Through the Dialogue of Cultures to the Development of Socio-Cultural Competences of the University Teachers
}

\author{
Elena I. Mychko ${ }^{1}$, Anna B. Serykh ${ }^{2}$, Elena V. Potmenskaya ${ }^{3}$, \\ Svetlana E. Mazanova ${ }^{4, *}$, Irina P. Kravchenko ${ }^{5}$, Tatyana I. Verbitskaya ${ }^{6}$, \\ Liliya I. Prikhozhaya ${ }^{7}$ and Ekaterina K. Shkvarova ${ }^{8}$ \\ 1, 2, 3, 8 Immanuel Kant Baltic Federal University, the Institute of Pedagogy, Kaliningrad, Russia \\ ${ }^{4,6}$ Immanuel Kant Baltic Federal University, the Resource Center (departments) of foreign languages, Kaliningrad, \\ Russia \\ ${ }^{5}$ Immanuel Kant Baltic Federal University, Institute of Economics, Management and Tourism, Kaliningrad, Russia \\ ${ }^{7}$ Immanuel Kant Baltic Federal University, the Institute of Humanities, Kaliningrad, Russia \\ *Corresponding author.Email: mazasnova@list.ru
}

\begin{abstract}
This study is an attempt to analyse the problem of the development of the socio-cultural competence of the teachers in the university. The purpose of the study is to develop a model for the development of the socio-cultural competence of the university teachers in the context of the dialogue of cultures. The study was based on a desk review of the terms "professional competence" and "socio-cultural competence", the authors have proved the interdependence of these concepts and their significance for the pedagogical activity of the university teachers. According to the theoretical analysis, the socio-cultural competence includes the knowledge in the field of common human culture; the readiness to carry out the intercultural communication in the specific social conditions; the communicative behaviour in accordance with the cultural norms and the communicative tolerance. The empirical study was carried out at the Baltic Federal University of Immanuel Kant. 59 teachers took part in the study as respondents. According to the results of the empirical research, $77 \%$ of teachers have a low level of formation of the communicative behaviour. It is especially important that the model for the development of a teacher's socio-cultural competence was developed thanks to the empirical data obtained. The novelty of the research consists in the ability to develop a model according to the principle of the dialogue of cultures, in which the learners are the active participants in the intercultural communication. The developed model can be used both in the refresher courses for the university teachers and in the preparation of the graduate students.
\end{abstract}

Keywords: Competence-based approach, Professional competence, Socio-cultural competence of a teacher, Dialogue of cultures.

\section{INTRODUCTION}

Nowadays, the process of increasing the world integration is taking place. This phenomenon leads to the mutual influence of cultures in a society. The number of foreign students studying at the Russian universities is increasing every year. Young people, whose culture differs in many respects from the Russian one, come to receive a higher education. Currently, students from 43 countries study at the Baltic Federal University of Immanuel Kant, so the university has two tasks: to prepare specialists in their field and teach them to communicate with people of different cultures. Thus, the students need to master the socio-cultural competence, and a university teacher needs to become proficient in the socio-cultural competence. Consequently, the skills of the intercultural communication, the non-verbal communication, the use 
of the information technologies and the consultative and communicative interaction acquire a priority value in the university. With this context, the question of the importance of the socio-cultural competence for teachers requires a detailed study.

Considering the concept of "socio-cultural competence" a philosopher A.P. Sadokhin defines it as "intercultural competence" [1], while Poshtareva T.V. considers the concept of "socio-cultural competence" as "ethno-cultural competence" [2]. Currently, more than 500 definitions of this concept are known. Such a large number of concepts is explained by the fact that this concept is considered by different sciences such as philosophy, sociology of culture, cultural studies and linguistics. We will not give a deep analysis of each of them. In this regard, we decided to focus on several methodological approaches.

The anthropological approach considers culture as a man's way of life [3]. In the philosophical studies of S.I. Hesse (1995) the culture unites civilization, citizenship and education [4]. In the studies of culturologist E.A. Orlova (1994), culture is considered as an example of human relations [5]. The psychology of education distinguishes an independent cultural-historical approach $[6,7]$.

The socio-cultural approach is important for our research because its approach is understood as the unity of culture and society in the translation of the values of different types of activity [8,9]. Professional skills and skills must be given the priority over the knowledge. It is the competent specialist who is capable of working efficiently at the level of world standards. Not only is he ready for continuous professional growth but also for professional mobility.

The article by D. McClelland was one of the first publications that raised the issue of the competent education [10]. It noted the need to test the competence, not the intelligence. According to the Russian studies, it is important to transform the educational process in such a way that the students acquire only those competencies which they need for their future profession $[11,12,13]$. The researchers also set the task of forming students' readiness to use the professional competencies in real practice. Some foreign researchers consider the competence as a person's ability. J. Raven understands the competence as a special ability of a person, which includes narrow special knowledge, skills, ways of thinking and responsibility for the result [14]. T. Hyland defines "competence" as the ability to perform specific activities in accordance with the standard [15]. It can be concluded that the competence is considered as a characteristic of a person and a result of the professional training.

The analysis of the pedagogical researches has revealed the fact that scientists identify the key competencies that are necessary for performing the professional activities. Being universal such key competencies as communicative, organizational, managerial and reflective can be used in the related fields of the activity. They are considered to be extremely important for various professional activities. I.A. Zimnyaya identifies the following types of the key competencies: the personality competence, the activity competence and the social interaction competence [16]. According to I.A. Zimnyaya, these key competencies need to be mastered in the process of the professional training.

Such scholars as N.V. Kuzmina, A.A. Derkach, A.K. Markova have called the key competencies as the professional competences and noted the harmonious combination of the professional excellence, the professional communication and the professional values $[17,18]$.

The foreign researchers have distinguished two components in the professional competence of the university graduates: "key competence" and "core competences" [19]. "Key competence" is considered as the ability of an employee to solve the professional tasks that appear in the process of building a professional career. This competence develops in such academic disciplines as "Information Technology", "Contemporary Problems". "Core competences" show the flexibility and mobility of a specialist in a rapidly changing environment. "Core competences" develops during the study of such training courses as "Small projects", "Collaboration" and others.

Despite the diversity and versatility of the definitions of the concept of "professional competence", the authors have agreed that it has a generalized character. This competence includes the subject, the technological, the didactic, the reflective and the communicative competences. Socio-cultural competence is also considered to be an important building block of the professional competence.

Being formed in the process of education and vocational training, the socio-cultural competence is a quality of a specialist's personality. The structure of the socio-cultural competence includes:

-The knowledge in the field of common human culture;

-The readiness to carry out the intercultural communication in the specific social conditions;

-The communicative behaviour in accordance with the cultural norms;

- The communicative tolerance.

Having analyzed the scientific literature, we have come to the conclusion that the problem of the sociocultural competence of the teacher has been considered 
quite recently. The development of the socio-cultural competence among the university teachers and the insufficient methodological and technological supports for this process are the hot spots of this study. Having analyzed the experience of higher educational institutions, we have come to the conclusion that not all teachers have this competence at a sufficient level. The main reason for this is the lack of experience in the intercultural communication, which creates the communication barriers and gives a rise to the fear of failure. With this context, the contradiction between the objective need to organize the communicative interaction in the educational society of the university and the insufficiently created conditions for this can be noted.

In an effort to find a solution to this contradiction, we were able to define the purpose of our scientific research, which was to develop a model for the development of the socio-cultural competence among the university teachers through the dialogue of cultures.

The research included several stages. Firstly, at the preparatory stage we have described the structure of the socio-cultural competence. Secondly, at the ascertaining stage we have carried out the diagnostics of the formation of the components of the socio-cultural competence of the university teachers. Thirdly, at the main stage we have developed a model for the development of the socio-cultural competence of the university teachers. Last, we have analyzed the data that were obtained at the control stage and predicted the prospects for the further activities.

\section{METHODS AND MATERIALS}

We analyzed and summarized the scientific works of both the Russian and foreign researchers in the field of the professional pedagogical education. We also used a set of the diagnostic techniques in the empirical part of the study. 59 lecturers from the Baltic Federal University of Immanuel Kant took part in the study. We especially note that the socio-cultural competence does not lend itself to diagnosis by the means of a single method. In this regard, we conducted the following studies: determined the knowledge in the field of the human culture and the communicative behaviour in accordance with the cultural norms (testing method: the tests contained complex questions that required the cultural knowledge); determined the willingness to carry out the intercultural communication in the specific social conditions (test "Diagnostics of acceptance of others" scale by Fejya) and measured the communicative tolerance (questionnaire "Tolerance Index" by G.U. Soldatov).

When processing the obtained data, we used the following formula: $\mathrm{Ka}=\mathrm{M} / \mathrm{N}$, where, $\mathrm{a}$ is the number of operations required to solve the tests and the situational tasks; $\mathrm{M}$ is the number of correctly solved tasks in the tests and the situational tasks; $\mathrm{N}$ is the total number of the answers to the test items and the situational tasks. Hence, we received the following data on the availability of the knowledge in the field of the common human culture and the skills of the practical communication in the field of the intercultural communication: we defined the levels as "optimal" at $\mathrm{Ka} \geq 0.9$; "Stable" at $0.7 \leq \mathrm{Ka}<0.9$; "Low" at $\mathrm{Ka}<0.7$. The level of the readiness to carry out the intercultural communication in the specific social conditions was determined by using the following criteria: "optimal" at $\mathrm{Kp} \geq 60$; "Stable" at $46 \leq \mathrm{Kp}<60$; "Low" at $\mathrm{Kp} \leq 45$. The criteria for determining the level of the communicative tolerance are as follows: "optimal" at Kt $\geq 100$; "Stable" at $80 \leq \mathrm{Kt} \leq 99$; "Low" at $\mathrm{Kt}<80$.

In order to conduct a consistent and in-depth analysis of the issue under the research, we decided to use the modelling method, since this method is considered to be universal, on the one hand, and it provides a consistent and in-depth study of the problem under the study, on the other hand. As a result, we have constructed a model, in which we have specified its main components and identified the dependencies among them. The method of statistical processing (criterion of signs G) was used to assess the effectiveness of the model for the development of the socio-cultural competence.

\subsection{Results}

At the ascertaining stage, we obtained the results that allowed us to determine the level of teachers' knowledge in the field of the universal human culture as "optimal" (62.64\%). Most teachers have a fairly clear knowledge of the cultural characteristics, traditions, values and norms. $26.86 \%$ of teachers have a "stable" level of knowledge, and $10.5 \%$ of teachers have a fragmentary level of knowledge. The results of the diagnostics of teachers' readiness to carry out the intercultural communication in the specific social conditions showed that $53 \%$ of teachers have an "optimal" level of readiness; $25.6 \%$ of teachers have a "stable" level of readiness, and $21.4 \%$ of teachers have a "low" level of readiness. Indicators of a "low" level of readiness may be associated with the fact that the teachers are not self-assured and experience the psychological barriers.

The results of the study of the communicative behaviour showed that only $4.65 \%$ of the teachers have an "optimal" level. $17.98 \%$ of the teachers have a "stable" level and $77.37 \%$ of the teachers have a "low" level. Hence, we came to the conclusion that it is necessary to form the communicative behaviour of teachers, since it largely determines the socio-cultural competence of teachers. When diagnosing the communicative tolerance of the teachers, we obtained 
the following results: $44.2 \%$ of the teachers have an "optimal" level, $37.95 \%$ of the teachers have a "stable" level and $17.85 \%$ of the teachers have a "low" level.

The results obtained allowed us to proceed to the main stage of the study. The main task of this stage was to actualize the development of the model for the development of the socio-cultural competence among the university teachers through the dialogue of cultures.

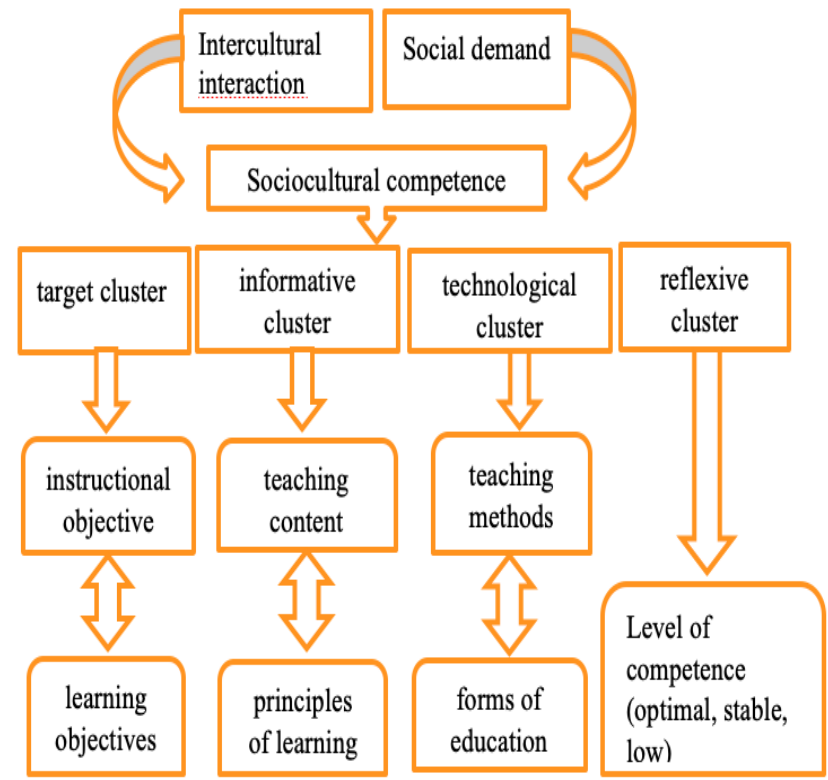

Figure 1. The model for the development of the sociocultural competence of the university teacher

Having carried out the control stage of the study, we obtained the intermediate results on the secondary diagnosis of the teachers' readiness to carry out the intercultural communication in the specific social conditions. These data are presented in Table 1.

Table 1.Dynamics of changes in the teachers' readiness to carry out the intercultural communication (in \%)

\begin{tabular}{|l|c|c|}
\hline Levels & $\begin{array}{l}\text { Primary } \\
\text { measurement }\end{array}$ & $\begin{array}{l}\text { Control } \\
\text { measurement }\end{array}$ \\
\hline Optimal & 53,0 & 55,9 \\
\hline Stable & 25,6 & 30,5 \\
\hline Low & 21,4 & 13,5 \\
\hline
\end{tabular}

The criterion of $G$ signs allowed us to record a positive shift, which shows that the level of the teachers' readiness to carry out the intercultural communication in the specific social conditions has changed in a positive direction. These values indicate the effectiveness of our model in implementing.

\section{DISCUSSION}

The main stage of our research allowed us to solve the main problem, which was to develop a model that allowed us to optimize the process of developing the socio-cultural competence of the university teachers. The competence-based approach allowed us to develop a theoretical basis for this model. We have highlighted the target, content, technological and reflective clusters in the model. The target cluster is focused on the teacher's achievement of the optimal level of formation of the socio-cultural competence. The objectives of our model were: the theoretical, the practical and the personal training of the teachers for the effective solution of the professional problems in the field of the intercultural interaction. The content cluster was determined by the principles and content of the training. The content of the training is focused on the common human culture: the values, the norms and the traditions. The training was based on the principles of ethics, integration and professional orientation. The leading principle was the dialogue of cultures. As the methods and techniques that supported the functioning of the technological cluster, we chose the interactive teaching methods (moderation method, case-study, business games and communication trainings). The reflexive cluster represents a synthesis of such criteria as the possession of the socio-cultural knowledge, the communication skills and the socio-cultural tolerance. The evaluation of these criteria makes it possible to determine the level of formation of the socio-cultural competence among the teachers (optimal, stable, low).

The principle of the dialogue of cultures, which is the key in implementing our model, allowed us to integrate the content and the technological clusters. This became possible due to the fact that the principles of the dialogue of cultures are based on the techniques and methods that allowed to motivate the teachers to communicate actively and productively. The dialogue of cultures helps to interact effectively with the representatives of different countries, cultures and linguistic communities [20]. The training of the teachers based on the principle of the dialogue of cultures required initiating the intercultural contact, maintaining the intercultural interaction with the aim of the cultural enrichment, identifying the situations of the cultural differences, and respecting the values of the representatives of different cultures.

The results, which were obtained after the secondary measurement, indicate that the changes that have occurred are not caused by the random factors. These changes are a consequence of the implementation of our model for the development of the socio-cultural competence of the university teachers through the dialogue of cultures. The teachers' needs for the interaction and mutual enrichment were met through the training based on the model that we developed.

\section{CONCLUSION}

We find that the high-quality intercultural interaction is possible only if the individual has 
developed the socio-cultural competence. Through the dialogue of cultures, it is possible to expand the knowledge in the field of the universal human culture; ensure the readiness to carry out the intercultural communication in the specific social conditions; to form the communicative behaviour in accordance with the cultural norms and the communicative tolerance. The novelty of our research lies in the fact that we have substantiated the possibility of purposeful development of the socio-cultural competence of the university teachers as one of the key ones in their professional activities. For this, we have developed a model for the development of the socio-cultural competence of the university teachers, which reflects the goal, content and actions of the subjects and expected the results. The pedagogical modelling is the goal of the educational process, since it makes it possible to prepare a modern teacher who acquires the necessary professional (sociocultural) competence in a short time. The practical significance of our research lies in the fact that the developed model can be used both in the refresher courses for the university teachers and in the preparation of the graduate students. We intend to use the results of our research to create a special training course based on the developed model, which optimize the curriculum to prepare the future teachers in the development of the socio-cultural competence.

\section{AUTHORS' CONTRIBUTIONS}

Elena I. Mychko: conceptualisation; collecting resources; developing the first draft with the incorporation of new ideas and relevant resources; methodology.

Anna B. Serykh: conceptualisation; conducting empirical research; re-writing the final draft.

Elena V. Potmenskaya: collecting references; writing the first draft; initial reviewing and crosschecking for references.

Svetlana E. Mazanova: collecting references; data curation; re-writing the final draft; final reviewing of the draft and final editing.

Irina P. Kravchenko: conceptualisation; methodology: initial reviewing; data curation.

Tatyana I. Verbitskaya: final reviewing of the draft and final editing; methodology; conducting empirical research.

Liliya I. Prikhozhaya: conducting empirical research; initial reviewing; cross-checking for references.

Ekaterina K. Shkvarova: data curation; reproduction of the diagrams.

\section{ACKNOWLEDGMENTS}

This study has been completed with the help of the administration of the Baltic Federal University of I. Kant, which provided an opportunity to conduct the empirical research at the university.

\section{REFERENCES}

[1] A.P. Sadokhin, Intercultural competence: concept, structure, ways of formation // Journal of Sociology and Social Anthropology. -2007. -T.X. -№1. -P. 130.

[2] T.V. Poshtareva, Formation of ethno-cultural competence // Pedagogy. -2005. -No. 3. -P.35-42.

[3] E.B. Taylor, Primitive culture. - M., 1989. -576 p.

[4] S.I. Gessen, Fundamentals of Pedagogy. Introduction to Applied Philosophy. - M., 1995. P.378.

[5] E.A. Orlova, An introduction to social and cultural anthropology. - M., 1994. - P.20.

[6] L.S. Vygotsky, Selected Psychological Research. M., $-1956 .-520 \mathrm{p}$.

[7] A.N. Leontiev, Activity. Consciousness. Personality. - M., 1977. -304 p.

[8] P. Sorokin, Man, civilization, society. -M., 1992. P.218.

[9] T. Parsons, Concept of culture and social system. M., 2002. -P.693-776.

[10]D.C. McClelland, Testing for competence than for « intelligence»// American Psychologist, 1973. Vol. 28. -pp.1-14

[11]E.F. Zeer, Competence-based approach to the modernization of vocational education // Higher education in Russia. -2005. -№4. -P.18-25.

[12] V.V. Serikov, V.A. Bolotov, Competence model: from idea to educational program // Pedagogy. 2003. -№10. -P.8-14.

[13]A.V. Khutorskoy, Key competencies: design technology // Public education. -2003. -№5. -P.5561.

[14][14] J. Raven, Competence in modern society. Identification, development and implementation. M., 2002. -396 p.

[15] T. Hyland, Book review of Competency Based Education and Training: A World Perspective by A. Arguelles and A. Gonczi (eds.)//Journal of Vocational Education and Training, 2001. Vol.53.3. -pp.487-490. 
[16]I.A. Zimnyaya, Key competencies - a new paradigm of the result of education // Higher education today. -2003. -№5. -P.34-42.

[17] N.V. Kuzmina, A.A. Derkach, Acmeology: ways to achieve the heights of professionalism. -M., 1993. $-116 \mathrm{p}$.

[18] A.K. Markova, Psychology of professionalism. M., 1996. -308 p.

[19]Atwan Ahmed, Evaluation of the technical education development in Bahrain, Research and development center. -Kingdom of Bahrain, 2005.pp.125-136.

[20] V.S. Bibler, Culture. Dialogue of cultures: experience of definition // Problems of Philosophy. -1989. -№6. -P.31-43. 